\title{
Multimedia Applications for MANETs over Homogeneous and Heterogeneous Mobile Devices
}

\author{
Saleh Ali Alomari and Putra Sumari \\ Universiti Sains Malaysia \\ Malaysia
}

\section{Introduction}

Mobile Ad Hoc Networks (MANETs) are considered a vital part in beyond third generation wireless networks (Nicopolitidis et al., 2003). In the matter of fact, they present a new wireless networking paradigm. Any sort of fixed infrastructure is not used by MANETs. They are important sorts of WLANs, therefore, in a distributed and a cooperative environment, MANETs do efficiently function (Murthy and Mano, 2004) (Sarkar et al., 2008). MANETs are networks of self-creating since there is a lack of routers, configuration prior to the network setup, Access Points (APs) and predetermined topology (Wu et al., 2007). MANETs are as well networks of self-administering and self-organizing. This is because in the network creation process, there is no application for central control. On MANETs, it is extremely hard to apply any of the central administration types, for instance, congestion control due to the dynamic nature of the network topology in MANETs, authentication or central routing. In short, several important applications benefited from MANETs, for example, in military, ubiquitous, emergency and collaboration computing.

In this chapter, describe the necessary background for the MANETs over homogeneous and heterogeneous mobile devices. The researcher begin this chapter to introduce the related background and main concepts of the Mobile Ad Hoc Network (MANETs) in Section 1.2, and explained briefly about the existing wireless mobile network approaches, wireless ad hoc networks, wireless mobile approaches in Section 1.2.2. The characteristic of MANETs are in Section 1.2.3. The types of Mobile Ad hoc network in Section 1.2.4. The traffic types in ad hoc networks which include the Infrastructure wireless LAN and ad hoc wireless LAN are presented in Section 1.2.5. In Section 1.2.6 highlight the relevant details about the ad hoc network routing protocol performance issues. The types of ad hoc protocols such as (Table-driven, On-demand and Hybrid) and Compare between Proactive versus Reactive and Clustering versus Hierarchical are in Section 1.2.7. And Section 1.2.8 respectively. The existing ad hoc protocols are presented in Section 1.2.9. The four important issues significant in MANET are Mobility, QoS Provisioning, Multicasting and Security is presented in Section 1.2.10. Furthermore, the practical application and the MANET layers are shown in Section 1.2.11 and Section 1.2.12 respectively . Finally, in Section 1.2.13 the summary of this chapter.

\subsection{Overview of MANETs}

The main concept of Wireless Local Area Networks (WLANs) refers to MANETs which are also called either infrastructure-based wireless networks or a single hop network 


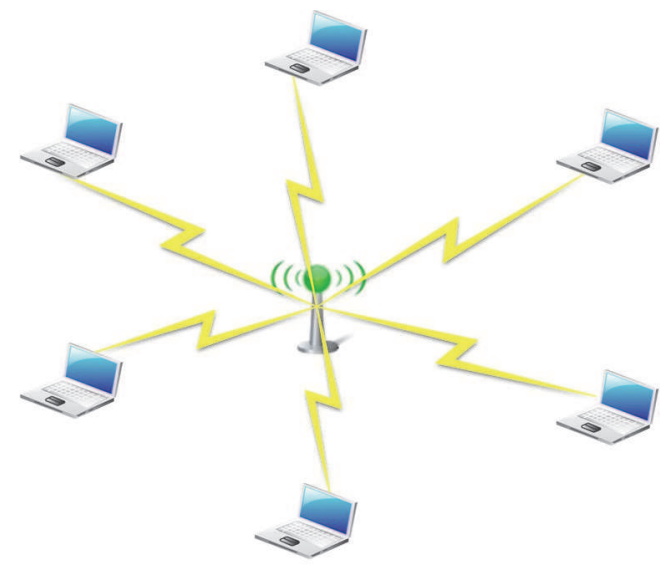

Fig. 1. Illustrates of a single hop WLAN with one AP

(Nicopolitidis et al., 2003) (Murthy and Mano, 2004). Inside a WLAN, the transmission is governed by at least one fixed Access Point (AP) between different mobile nodes. An existing network backbone and the stations contain a bridge as AP functions (Basagni et al., 2004). Both QoS and security issues are efficiently controlled by the AP within a particular network. Inside the network of WLAN, there is no need for different mobile nodes since the $\mathrm{AP}$ is the source that does communication through a single hop manner. Wireless network standards are included by the WLAN implementations and developed by Institute of Electrical and Electronics Engineers (IEEE) 802 project (IEEE 802.11, IEEE 802.11b, IEEE 802.11g, IEEE 802.11a, and IEEE 802.11n) and High Performance Radio Local Area Network Type 2 (HiperLAN2). In addition, the European Telecommunications Standardization Institute (ETSI) Broadband Radio Access Networks (BRAN) project (ETSI, 1999) developed the European version of IEEE 802.11a. A frequency of 2.4GHz runs for these standards. However, 5GHz runs for the IEEE 802.11a. For these standards, the transmission rates (bandwidths) are $2 \mathrm{Mbps}$ where as for IEEE 802.11a and IEEE 802.11g, $54 \mathrm{Mbps}$ is run. For IEEE 802.11b, 11 Mbps is run and for IEEE 802.11n, $100 \mathrm{Mbps}$ is run. Note that a single hop WLAN with one $\mathrm{AP}$ is shown in Figure 1.

For mobile hosts, a new wireless networking paradigm indicates to a MANET. All sorts of fixed infrastructure are independent to MANET. In order to maintain a connection within the network, nodes (hosts) will rely on each other through a manner that is to be cooperative. Therefore, both computing and ubiquitous communication are considered to be two goals of mobile ad hoc networking. In the matter of fact, both of them are rapidly deployed in such a way they do not rely on a pre-existing infrastructure, for example, Base Station (BS) and Access point (AP) (Perkins et al., 2002). A peer to peer network refers to MANET which has the ability to allow a communication between each wireless client that relies on any infrastructure. MANET can also be defined as a mobile nodes collection of which a highly resource constrained network and a dynamic topology are formed by this collection (Mohapatra and Krishnamurthy, 2005) (Murthy and Mano, 2004). A single hop network refers to WLAN, Major functions within the network are being performed by the cooperation of the nodes. This process represents a mutli-hop network that refers to the MANET. There are such problems entitled in MANETs. These comprise; security, QoS, routing and energy conversation. These problems came due to several reasons: high mobility, resource constrains such as power, storage, and bandwidth (Negi and Rajeswaran, 2004), its cooperative nature 
and the dynamic topology of nodes operating in MANET's environment. In Defence Advanced Research Projects Agency (DARPA) Packet Radio projects (Jubin et al., 1987), ad hoc networking was initiated for military applications, specifically, for dynamic wireless networks since 1970s. Accordingly, this networking is not considered to be as a new concept. For MANET, a new networking group was formed within the Internet Engineering Task Force (IETF-manet) so that the standard Internet routing support could be developed for mobile IP autonomous segments. In addition, a framework for IP-based protocols in MANET will be developed as well. In the fields of mobile IP-based networks and wireless internet, the increasing improvement in the recent IEEE standards of 802 projects for wireless networks (Broch.J et al., 1998) has raised up. A MANET can be either heterogeneous or homogeneous depending on the type of mobile nodes being involved. When all mobile nodes are of the same type of a MANET, this is called a homogeneous MANET, whereas when different type of mobile nodes are involved, this is otherwise called a heterogeneous MANET. The homogeneous and heterogeneous mobile ad hoc network are shown in In Figure 2 and Figure 3 respectively. The same family of IEEE 802.11 standards is being used by MANETs. More

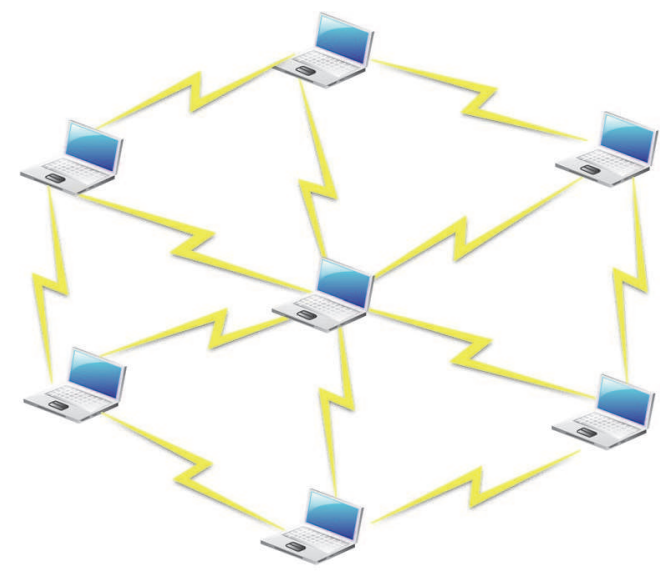

Fig. 2. Illustrates the homogeneous mobile ad hoc network

specifically, in Bluetooth and WLANs, these standards are being used (Morinaga et al., 2002). Table 1 shows a comparison between WLAN and MANET.

\subsection{Mobil Ad Hoc Network}

With the widespread rapid development of computers and the wireless communication, the mobile computing has already become the field of computer communications in high-profile link. MANET (Sarkar et al., 2008) is a completely wireless connectivity through the nodes constructed by the actions of the network, which usually has a dynamic shape and a limited bandwidth and other features, network members may be inside the laptop, Personal Digital Assistant (PDA), mobile phones and so on. On the Internet, the original mobility is the term used to denote actions hosts roaming in a different domain; they can retain their own fixed IP address, without need to constantly changing, which is Mobile IP technology.

Mobile IP nodes in the main action is to deal with IP address management, by home users and foreign users to the mobile node to packet tunneling, the routing and fixed networks are not different from the original. However, ad hoc network to be provided by mobility is a fully wireless, can be any mobile network infrastructure, without a base station, all 


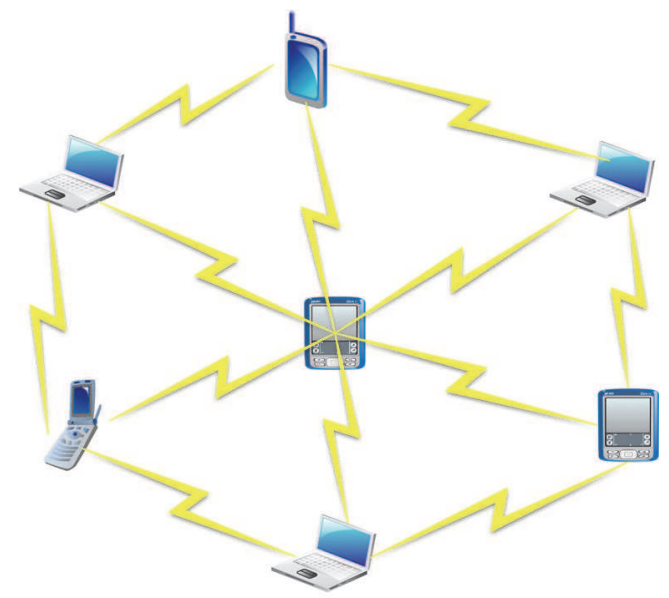

Fig. 3. Illustrates the heterogeneous mobile ad hoc network

\begin{tabular}{lll}
\hline Comparison Aspect & (WLAN) & (MANET) \\
\hline Autonomous terminals & No & Yes \\
Self-configuration & No & Yes \\
Mobile host/router & No & Yes \\
Bandwidth constrained network & No & Yes \\
Infrastructure-based & Yes (APs/routers/Servers) & No \\
Power awareness & Does not matter & Yes \\
Security policy & Centralized & Distributed \\
Centralized/distributed operation & Centralized & Distributed \\
Routing & Easy & A bit difficult \\
Scalability & Easy & A bit difficult \\
Multicasting & Easy & A bit difficult \\
Static/ dynamic topology & Static & Dynamic \\
QoS guarantee & Can be guaranteed easily & A bit difficult \\
Typical applications & Home, enterprise network & Military/emergency \\
Single hope / multi hope & Single & multi \\
Communication mechanism & Base station type access & P2P \\
\hline
\end{tabular}

Table 1. Illustrates the comparison between WLAN and MANET

the nodes can contact each other at the same time take router work with the Mobile IP completely different levels of mobility. Early use of the military on the Mobile Packet Radio Networked (MPRN )in fact can be considered the predecessor of MANET, when the high-tech communication equipment, the size, weight continuously decreases, power consumption is getting low, Personal Communication System (Personal Communication System, PCs) concept evolved, from the past few years the rapid popularization of mobile phones can be seen to communicate with others at anytime and anywhere, get the latest information, or exchange the required information is no longer a dream. And we have gradually become an integral part of life. Military purposes, as is often considerable danger in field environment, some of the major basic communication facilities, such as base stations, may not be available, 
in this case, different units, or if they want to communicate between the forces, they must rely on MANET networks infrastructure. In emergency relief, the mountain search and rescue operations at sea, or even have any infrastructure can not be expected to comply with the topographical constraints and the pressure of time under the pressure, ad hoc network completely wireless and can be any mobile feature is especially suited to disaster relief operations when personal communication devices and more powerful, some assembly occasions, if need to exchange large amounts of data, whether the transmission of computer files or applications that display. if can connect with a temporary network structure, then the data transmission will be more efficient without the need for large-scale projection equipment would not have point to point link equipment such as network line or transmission line. The current wireless LAN technology, Bluetooth is has attracted considerable attention as a development plan. Bluetooth's goal is to enable wireless devices to contact with each other, if sentence formation adding the design MANET.

\subsubsection{History of Ad Hoc Network}

Nowadays, the information technology will be mainly based on wireless technology, the conventional mobile network and cellular are still, in some sense, limited by their need for infrastructure for instance based station, routers and so on. For the MANET, this final limitation is eliminated. The ad hoc network are the key in the evolution of wireless network and the ad hoc network are typically composed of equal node which communication over wireless link without any central control. Although military tactical communication is still considered as the primary application for MANET and commercial interest in this type of networks continues to grow. And all the applications such as rescue mission in time of natural disasters, law enforcement operation, and commercial as rescue and in the sensor network are few commercial examples, but in this time it's become very important in our life and they become use it.

The MANET application is not new one and the original can be traced back to the Defence Advanced Research Projects Agency (DARPA), Packet Radio Networking (PRNET) project in 1972 (Freebersyser and Leiner, 2001, Jubin and Tornow, 1987) which evolved into the survivable adaptive radio networks (SURAN) program. Which was primarily inspired by the efficiency of the packet switching technology for instance the store/forward routing and then bandwidth sharing, it's possible application in the MANET environments. As well commercial rescue in the PRNET devises like repeaters and routers and so on, were all mobile although mobility was so limited in that time, theses advanced protocol was consider good in the 1970s. After few years advance in micro electronics technology and it's was possible to integrate all the nodes and also the network devices into a single unit called ad hoc nodes, and then the advance such as the flexibility, resilience also mobility and independence of fixed infrastructure, and in that time they so interesting to use it immediately among military battlefield, Ad hoc networks have played an important role in military applications and related research efforts. For example, the global mobile information systems (GloMo) simulator (Leiner et al.), the near-term digital radio (NTDR) program and also has been the increase in the police, commercial sector and rescue agencies in use of such networks under disorganized environments. Ad hoc network research stayed long time in the realm of the military. And in the middle of 1990s with advice of commercial radio technology and the wireless became aware of the great advantages of MANET outside the military battlefield domain, and then became so active research work on ad hoc network start in 1995 in the conference session of the Internet Engineering Task Force (IETF) (IETF-MANET). And then in 1996 this works had evolved into MANET, in that time focused to discussion centered in military satellite network, wearable computer network and tactical network with 
specific concerns begin raised relative to adaptation of existing routing protocols to support IP network in dynamic environments, as well as they make the charter of the MANET Working Group (MANETWG) of the Internet Engineering Task Force (IETF) also the work inside the MANETs relies on other existing IETF standard such as Mobile IP and IP addressing. Most of the currently available solutions are not designed to scale to more than a few hundred nodes. Currently, the research in MANET became so active and vibrant area and the efforts this research community together with the current and future (MANET) enabling radio technology.

Recently, the Ad Hoc Wireless Network and computing consortium was established with the aim to coalescing the interests and efforts to use it anywhere such as academic area and industry and so on. And in order to apply this technology to application ranging for the Home Wireless (HW) to wide area peer to remote networking and communications. And it does will certainly pave the way for commercially viable MANETs and their new and exciting applications, which began to appear in all fields in this life. More recently, the computer has became spread significantly in the all the place and after a pervasive computing environment can be expected based on the recent progresses and advances in computing and communication technologies. Next generation of mobile communications will include both prestigious infrastructure wireless networks and novel infrastructureless MANETs.

\subsubsection{Wireless Ad Hoc Networks}

MANET is a collection of two or more devices or terminals with wireless communications and networking capability that communicate with each other without the aid of any centralized administrator also the wireless nodes that can dynamically form a network to exchange information without using any existing fixed network infrastructure. And it's an autonomous system in which mobile hosts connected by wireless links are free to be dynamically and some time act as routers at the same time. All nodes in a wireless ad hoc network act as a router and host as well as the network topology is in dynamically, because the connectivity between the nodes may vary with time due to some of the node departures and new node arrivals. The special features of MANET bring this technology great opportunity together with high challenges. All the nodes or devises responsible to organize themselves dynamically to communication between each other and to provide the necessary network functionality in the absence of fixed infrastructure or can call it ventral administration. It implies that maintenance, routing and management, etc, have to be done between all the nodes. This case called peer level multi hopping and that is the main building block for ad hoc network. In the end, conclude that the ad hoc nodes or devices are difficult and more complex than other wireless networks. Therefore, ad hoc networks form sort of clusters to the effective implementation of such a complex process. In Figure 4 shows some nodes forming ad hoc networks, and there are some nodes more randomly in different directions and different speeds.

In the past few years, the people became realized to use all the technology so widely and the people's future living environments are emerging, based on information resource provided by the connections of different communication networks for clients also have seen a rapid expansion in the field of mobile computing because the proliferation not expensive, widely available wireless devices. A new small devices such as personal communication like cell phones, laptops, Personal Digital Assistants (PDAs), handhelds, and there are a lot of traditional home appliances such as a digital cameras, cooking ovens, washing machines, refrigerators and thermostats, with computing and communicating powers attached. Expand this area to became a fully pervasive and so widely. With all of this, the technologies must be 


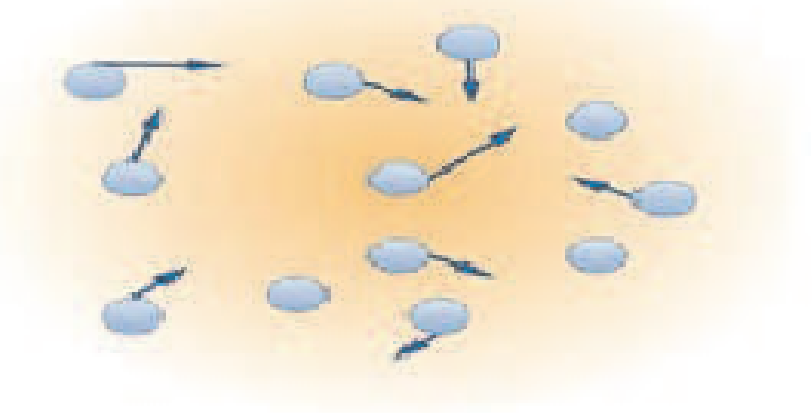

Fig. 4. Illustrates some of the nodes moves randomly in different direction and different speeds

formed the good and new standard of pervasive computing, that including the new standards, new tools, services, devices, protocols and a new architectures.As well as the people in this time, or the users of internet users in ad hoc network through increase in the use of its advantage is that not involve any connection link and the wiring needed to save space, and building low cost, and improve the use, and can be used in mobile phone, because of these advantage local wireless network architecture readily. And beads in these advantages the wireless network can be used in the local area network terminal part of the wireless (Liu and Chang, 2009).

\subsubsection{Wireless mobile network approaches}

The past decade, the mobile network is the only one much important computational techniques to support computing and widespread, also advances in both software techniques and the hardware techniques have resulted in mobile hosts and wireless networking common and miscellaneous. Now will discuss about to distinct approaches very important to enabling mobile wireless network or IEEE 802.11 to make a communication between each other (part-11, 1997) (part-12, 1999). Firstly infrastructure wireless networks and secondly, infrastructureless wireless networks (ad hoc networks) and will clarify both in bottom.

\subsubsection{Infrastructure wireless networks}

In this architecture that allow the wireless station to make a communication between each other through the Base Station (BS) as shown in Figure 5, and that will handover the offered traffic from the station to another, the same entity will regulate or organize the allocation of radio resources. When a source node likes to communicate with a destination node, the former notifies the BS. At this point, the communicating nodes do not need to know anything about the route from one to another. All that matters is that the both source and destination nodes are within the transmission range for the BS and then if there is any one loses this condition, the communication will frustration or abort.

\subsubsection{Infrastructureless wireless networks}

The mobile wireless network is known as Mobile Ad Hoc Network (MANET). As has been previously defined in the bidder is a collection of two or more devices or nodes or 


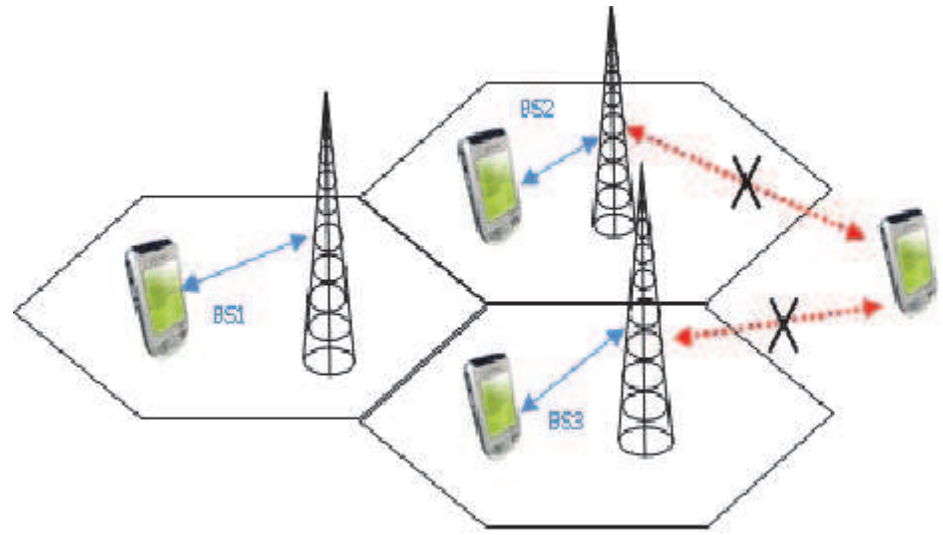

Fig. 5. Illustrates of the infrastructure network

terminals with wireless communications and networking capability that communicate with each other without the aid of any centralized administrator also the wireless nodes that can dynamically form a network to exchange information without using any existing fixed network infrastructure. And it's an autonomous system in which mobile hosts connected by wireless links are free to be dynamically and some time act as routers at the same time (Frodigh et al., 2000). The infrastructureless is important approaches in this technique to communication technology that supports truly pervasive computing widely duo to there is a lot of context information need to exchange between mobile nodes but can not rely on the fixed network infrastructure, but in this time the communication wireless became develops very fast (IETF-manet). In Figure 6 shown a small example for the ad hoc networks, to explain how mobile ad hoc network working.

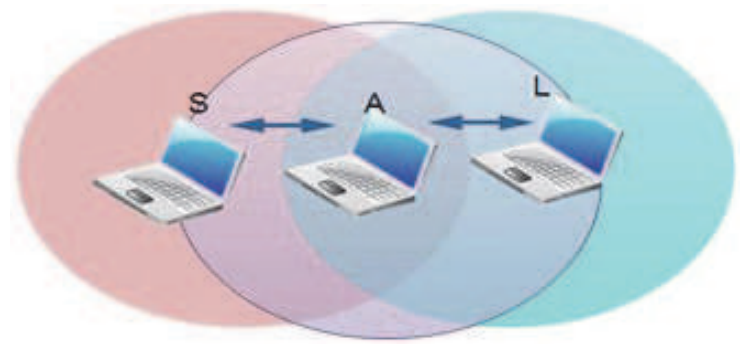

Fig. 6. Illustration of the infrastructureless networks (ad hoc networks)

This figure illustrates the modus operandi of ad hoc networks, there are a three ad hoc network nodes (S, A, L), the source node (S) need to make a communication with the destination node (L) and both of them (S, L) not in the same transmission range of each others, here both they must use the node (A) to send and receive or forewords the packets from source to the destination that means from node to another node.(R) is a node work as host and router in the same time. Additionally, the definition for the router is an entity that determines the path to be used, in order to forward a packet towards the last destination, and then the router chooses the next node to which a packet should be forwarded according to its current understanding of the state of the network. 


\subsubsection{Characteristics of MANET}

Request For Comments (RFC) 2501 document (IETF, 1999) which is published by MANET working group within the IETF describes the main characteristics of MANET which differs from the characteristics of traditional wireless local area networks such as WLANs due to the dynamic and the infrastructureless natures of MANETs (Hekmat, 2006). According to the IETF RFC 2501, MANET has characteristics can be divided into the following:

1. A collection of autonomous terminals means that within a MANET, each mobile node performs its tasks as a router and a host.

2. It contains a dynamic topology which means there are a group of nodes into it that are moving and resulting to a random change rapidly at unpredictable times through the network topology.

3. A distributed operation is contained into it which means that the network's management and control is spread (distributed) in the nodes because of the infrastructure types' absence of which the central control of the network operations is supported. In a MANET, nodes must perform with each other. each node behaves as a router and a host simultaneously in order to have the network functions efficiently implemented, for example, routing and security.

4. It can be deployed as fast as it could be.

5. Pre-existing infrastructure is independent from it.

6. Bandwidth-constrained, variable capacity links compared with the wired network environment, the capacity of the wireless link itself is relatively small, but also susceptible to external noise, interference, and signal attenuation effects.

7. Self-adapts to the propagation patterns and connectivity.

8. Adapts to mobility patterns and traffic.

9. A limited physical security is contained into it, for example, in the absence of any centralized encryption or authentication. In order to reduce security threats, existing techniques of link security are at most applied into the WLANs and the wired networks.

10. It has an energy constrained operation a laptop or handheld computers are often used batteries to provide power, how to save electricity in the context of depletion of system design is also necessary to consider the point.

Mobile networking and MANETs are considered to be of good candidates due to many reasons: its simplicity for usage, robustness, speedy deployment and low cost. Its disadvantages comprise the complexity of routing due to the consistent move of nodes, mobility and dynamic topology, vulnerability of security due to the cooperation principle in MANETs, and the low computing power due to small devices used in MANETs.

\subsubsection{Types of mobile ad hoc network}

The wireless ad hoc network divided into three main types. Firstly, the quasi-static ad hoc network the nodes may be portable or static, because the power controls and link failures, the resulting network topology may be so active. The sensor network is an example for the quasi-static ad hoc network (Estrin et al., 1999). Secondly, the MANET the entire network may be mobile and the nodes may move fast relative to each other.thirdly, Vehicular Ad Hoc Networks (VANETs) are a kind of network useful for offering traffic information interchange in a collaborative way between vehicles. 


\subsubsection{Mobile Ad Hoc Networking (MANET)}

MANET is a group of independent network mobile devices that are connected over various wireless links. It is relatively working on a constrained bandwidth. The network topologies are dynamic and may vary from time to time. Each device must act as a router for transferring any traffic among each other. This network can operate by itself or incorporate into large area network (LAN).

There are three types of MANET. It includes Vehicular Ad hoc Networks (VANETs), Intelligent Vehicular Ad hoc Networks (InVANETs) and Internet Based Mobile Ad hock Networks (iMANET). The set of application for MANETs can be ranged from small, static networks that are limited by power sources, to large-scale, mobile, highly dynamic networks. On top of that, the design of network protocols for these types of networks is face with multifaceted issue. Apart from of the application, MANET need well-organized distributed algorithms to determine network organization, link scheduling, and routing. Conventional routing will not work in this distributed environment because this network topology can change at any point of time. Therefore, we need some sophisticated routing algorithms that take into consideration this important issue (mobile network topology) into account. While the shortest path (based on a given cost function) from a source to a destination in a static network is usually the optimal route, this idea is not easily far-reaching to MANET. Some of the factors that have become the core issues in routing include variable wireless link quality, propagation path loss, fading, interference; power consumed, and network topological changes. This kind of condition is being provoked in a military environment because, beside these issues in routing, we also need to guarantee assets security, latency, reliability, protection against intentional jamming, and recovery from failure. Failing to abide to of any of these requirements may downgrade the performance and the dependability of the network.

\subsubsection{Mobile ad hoc sensor network}

A mobile ad hoc sensor network follows a broader sequence of operational, and needs a less complex setup procedure compared to typical sensor networks, which communicate directly with the centralized controller. A mobile ad hoc sensor or hybrid ad hoc network includes a number of sensor spreads in a large geographical area. Each sensor is proficient in handling mobile communication and has some level of intelligence to process signals and to transmit data. In order to support routed communications between two mobile nodes, the routing protocol determines the node connectivity and routes packets accordingly. This condition has makes a mobile ad hoc sensor network highly flexible so that it can be deployed in almost all environments (Bakht, 2010). The wireless ad hoc sensor networks (Asif, 2009) are now getting in style to researchers. This is due to the new features of these networks were either unknown or at least not systematized in the past. There are many benefits of this network, it includes:

- Use to build a large-scale networks

- Implementing sophisticated protocols

- Reduce the amount of communication (wireless) required to perform tasks by distributed and/or local precipitations.

- Implementation of complex power saving modes of operation depending on the environment and the state of the network.

With the above-mentioned advances in sensor network technology, functional applications of wireless sensor networks increasingly continue to surface. Examples include the replacement 
of existing detecting scheme for forest fires around the world. Using sensor networks, the detecting time can be reduced significantly. Secondly is the application in the large buildings that at present use various environmental sensors and complex control system to execute the wired sensor networks. In a mobile ad hoc sensor networks, each host may be equipped with a variety of sensors that can be organized to detect different local events. Besides, an ad hoc sensor network requires a low setup and administration costs (Akkaya and Younis, 2005) (Akyildiz et al., 2002).

\subsubsection{Vehicular Ad Hoc Networks (VANETs)}

Vehicular Ad Hoc Networks (VANETs) (Kosch et al., 2006) are a kind of network useful for offering traffic information interchange in a collaborative way between vehicles. They are foreseen to be a great revolution in the driving, providing new services such as Road safety, traffic management, Pollution reduction, Cost reduction in the vehicle security incorporation and public transport.

\subsubsection{The traffic types in the ad hoc networks}

The traffic types in the ad hoc networks are so differen from the infrastructure wireless network. The traffic types are classified into three types (peer to peer, remote to remote and dynamic traffic) (Mbarushimana and Shahrabi, 2008). Firstly, peer to peer is a communication between two nodes in the same area, that means which are within one hop. Network traffic (in bits per second) is usually fixed. Secondly, remote to remote is a communication between two nodes beyond a single hop, but maintain a stable route between them. This may be the result of a number of nodes, to stay within the range of each other in one area or may move as a group. Movement it's a similar to the standard network traffic. Finally, dynamic traffic it will happen when the nodes are movie dynamically around and then the routers must be reconstructed. This results in a poor connectivity and network activity in short bursts. For example in IEEE 802.11 network and the basic structure divided into two types firstly infrastructures wireless LAN, the second structure ad hoc wireless LAN.

\subsubsection{Infrastructure wireless LAN}

In this kind of network as shown in the Figure 7, the network in any architecture will be an access point; its function is one or more of the wireless local area network and the existing cable network systems to link, so that stations within the wireless local area network and external nodes can connect with each other. It is characterized by a fixed and pre-positioning a good base station location, the static backbone network topology, a good environment and a stable connection, the base station that is doing a good job when you set up detailed plans (Li, 2006).

\subsubsection{Ad hoc wireless LAN}

The ad hoc wireless LAN is an infrastructures relies on infrastructures wireless local area network, which only targeted at local area network within the framework of each machine is able to be linked up into networks, regardless of whether the communication with the outside world, then such a structure, either one or two users can communicate directly with each other, and this structure is composed of at least composed of two or more workstations. Is characterized by no fixed base stations, network will be rapidly changing; dynamic network topology is vulnerable to interference, to automatically form a network without infrastructure 


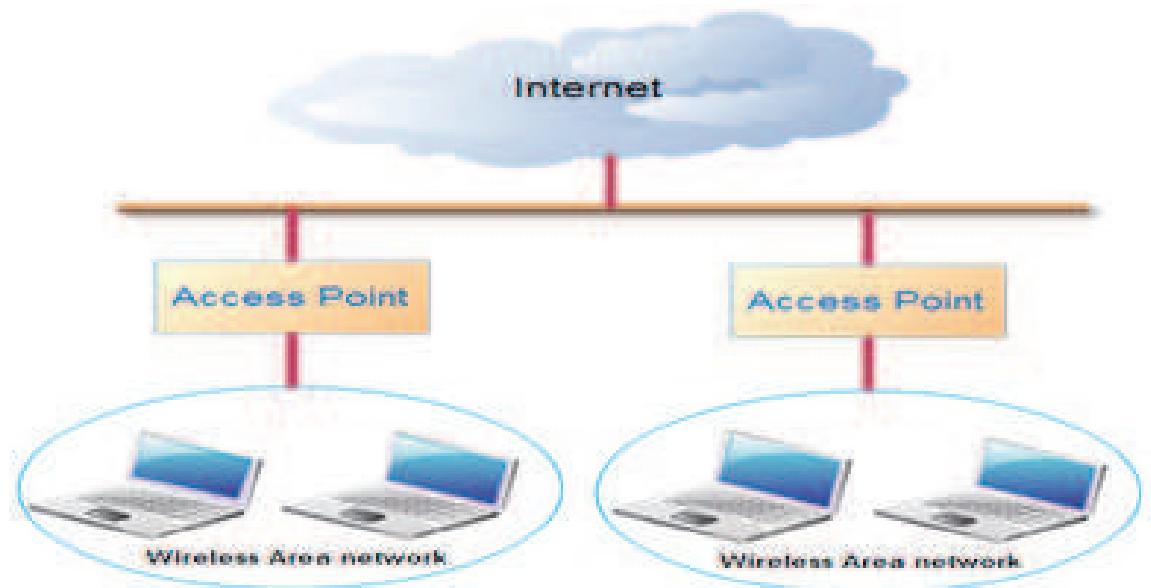

Fig. 7. Illustrates of the infrastructure wireless LAN architecture.

and adapt to topology changes. For more explain shows the Figure 8 for Ad Hoc Wireless network.
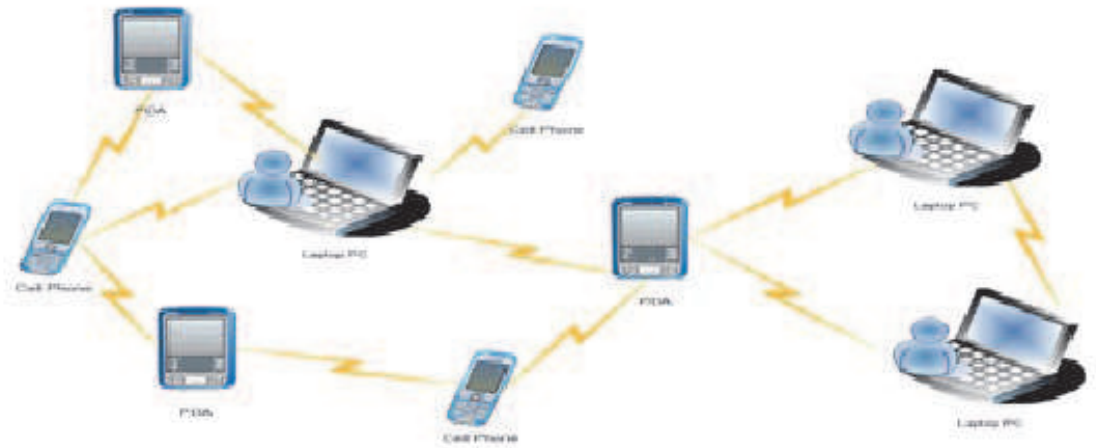

Fig. 8. Illustrates of the wireless ad hoc network

\subsubsection{Ad hoc network routing protocol performance issues}

The MANET with the traditional wired, fixed networks have many different characteristics, so to design a suitable routing protocol for MANET operating environment must also consider the different directions, the following sub-qualitative and quantitative aspects of the discussion:

1. On the qualitative aspects, can be divided into:

a) Distribution operation: Due to the existence of MANET where there is no prerequisite for the construction of the underlying network, so routing can not rely on a particular node to operate. 
b) Loop-freedom: All the routing protocol should be consistent with the characteristics; we must ensure the normal work in order to avoid waste of bandwidth.

c) Demand-based operation: In order to reduce the burden on each node, if the link is not so much the demand should be considered when using On-demand approach to the establishment of the path, and only when the need for a particular path query, the establishment of the path.

d) Proactive operation: With the On-demand concept of the contrary, if the network resources fairly adequate, proactive table-driven approach could speed up the path to the establishment of speed.

e) Security: Because it is the wireless environment, to how to ensure the security of the connection can not be ignored will be part of network security is also a MANET from theory to implementation of the key challenges.

f) Sleep Period operation: As the MANET nodes are generally smaller wireless devices, using the battery as a power supply, how to save power consumption, or for no work, the node goes into sleep mode, can operate more smoothly so that MANET. Also the nodes of a MANETs may stop transmitting or receiving or both, also even receiving requires power for arbitrary time periods and the routing protocol should be able to accommodate such sleep periods without overly adverse consequences. This property may require close coupling with the link-layer protocol through a standardized interface.

2. On the quantity, can be divided into:

a) End-to-end data throughput and delay: Data transmission rate and delay in the case that every routing protocol must take into account the focus should be how to find the best path? Is the maximum bandwidth or minimum latency, or the link to the most stable? Considered more likely to make more complicated routing protocol, but it is possible to significantly improve the transmission quality.

b) Route Acquisition time: While the table-driven generally higher than on-demand performance good, but many of the former to pay the price, which, if properly designed, for example, there is more commonly used in the path cache, or a certain fixed path, can improve the path to the establishment of time.

c) Percentage Out-of-order delivery: Real-time data for this part of the more stringent requirements, and general information will not affect how and upper TCP cooperation is also IP routing work.

d) Efficiency: The simplest method, the smallest control overhead done the most complete, most powerful feature is a common goal for all routing protocol.

\subsubsection{Types of ad hoc protocols}

Ad hoc network routing protocols is divided to three type of routing protocols, which that depending on a different of routing protocols (Saleh Al-Omari and Putra Sumari, 2010).

\subsubsection{Oriented routing table (table-driven)}

The oriented routing table is an active routing environment in which the intervals between the wireless nodes will send medical information with more paths. Each wireless node is on the basis of information gathered recently to change its route table, when the network topology change makes the original path is invalid, or the establishment of any new path, all nodes will receive updates on the status path. The path will be continuously updated, so that the node in time of peace on its own routing tables is ready, and immediately available 
when needed. However, such agreements must be periodically to broadcast messages, so a considerable waste of wireless bandwidth and wireless node power, but if you want to reduce the broadcast bandwidth consumption caused by a large number, we should lengthen the interval between each broadcast time, which in turn will result in the path table does not accurately reflect network topology changes.

\subsubsection{Demand-driven (on-demand)}

In the demand driven, When needed to send packets only it began to prepare to send the routing table. When a wireless node needs to send data to another wireless node, the source client node will call a path discovery process, and stored in the registers of this path. The path is not valid until the expiration or the occurrence of conditions of the agreement with the first phase of a ratio of such agreements in each node. A smaller amount of data needed, and do not need to save the entire network environment and the routing information. The main benefit of this agreement is that the use of a lower bandwidth, but the drawback is that not every wireless node that sends packets can always quickly find the path. The path discovery procedure can cause delays and the average delay time is longer (Liu and Chang, 2009).

\subsubsection{Hybrid}

Hybrid is an improvement of the above mentioned two, or the combination of other equipment, such as Global Positioning System (GPS) and other equipment, participate in the study of mechanisms to facilitate the routing of the quick search, and data transmission (Pandey et al., 2005) (Johnson and Maltz, 1999.). However, there are already more than 13 kinds of the above routing protocol have been proposed, following the more representative for several separate presentations, and to compare their individual differences lie.

\subsubsection{Compare between proactive versus reactive and clustering versus hierarchical}

\subsubsection{Proactive versus Reactive Approaches}

Ad hoc routing protocols can be classified into two types; proactive and On-Demand (reactive) base on each own strategy (Perkins, 2001). Proactive protocols demand nodes in a wireless ad hoc network to keep track of routes to all possible destinations. This is important because, whenever a packet requests to be forwarded, the route is beforehand identified and can be used straight away. Whenever there's modification in the topology, it will be disseminated throughout the entire network. Instances include "destination-sequenced distance-vector" (DSDV) routing (Perkins and Bhagwat, 1994), "wireless routing protocol" (WRP) (Murthy and Garcia-Luna-Aceves, 1996), "global state routing" (GSR) (Chen and Gerla, 1998), and "fisheye state routing" (FSR) (Iwata et al., 2002)and in next section will discuss about everyone.

On-demand (reactive) protocols will build the routes when required by the source node, in order for the network topology to be detected as needed (on-demand). When a node needs to send packets to several destinations but has no routes to the destination, it will start a route detection process within the network. When a route is recognized, it will be sustained by a route maintenance procedure until the destination becomes unreachable or till the route is not wanted anymore. Instances include "ad hoc on-demand distance vector routing" (AODV) (Perkings et al., 2003), "dynamic source routing" (DSR) (J.Broch et al., 2004), and "Cluster Based Routing protocol" (CBRP) (Jiang et al., 1999). Proactive protocols comprise the benefit that new communications with arbitrary destinations experience minimal delay, but experience the disadvantage of the extra control overhead to update routing information at all nodes. To overcome with this limitation, reactive protocols take on the opposite method by tracking down route to a destination only when required. Reactive protocols regularly utilize less 
bandwidth compared to proactive protocols, however it is a time consuming process for any route tracking activity to a destination proceeding to the authentic communication. Whenever reactive routing protocols must relay route requests, it will create unnecessary traffic if route discovery is required regularly.

\subsubsection{Clustering versus hierarchical approaches}

Scalability is one of the major tribulations in ad hoc networking. The term scalability in ad hoc networks can be defined as the network's capability to provide an acceptable level of service to packets even in the presence of a great number of nodes in the network. If the number of nodes in the network multiply for proactive routing protocols, the number of topology control messages will increases nonlinearly and it will use up a large fraction of the available bandwidth. While in reactive routing protocols, if there are a large numbers of route requests propagated to the entire network, it may eventually become packet broadcast storms. Normally, whenever the network size expands beyond certain thresholds, the computation and storage requirements become infeasible. At a time whenever mobility is being taken into consideration, the regularity of routing information updates may be extensively enhanced, and will deteriorate the scalability issues. In order to overcome these obstacles and to generate scalable and resourceful solutions, the solution is to use hierarchical routing. Wireless hierarchical routing is based on the idea of systematizing nodes in groups and then assigns the nodes with different task within and outside a group. Both the routing table size and update packet size are decreased by comprising only a fraction of the network. For reactive protocols, restricting the scope of route request broadcasts can assists in improving the competency. The best method of building hierarchy is to gather all nodes geographically near to each other into groups. Every cluster has a principal node (cluster head) that corresponds with other nodes. Instances of hierarchical ad hoc routing protocols include "zone routing protocol" (ZRP) (Haas and Pearlman, 2000).

\subsubsection{Existing ad hoc protocols}

In the ad hoc network there are more than 13 kinds of the above routing protocol have been proposed such as DSDV, GSR, CGSR, WRP, FSR, AODV, DSR, TORA, CBRP, ABR, SSR, CEDAR and ZRP, for more dilates about existing ad hoc network protocols (Saleh Alomari and Putra Sumari, 2010. Further explination for understanding some of the existing mobile ad hoc network are provided in Appendix A figure 10. The comparison between Table Driven, Demand Driven and Hybrid are shown in Table 2,and then show in Table 3 the Table Driven for three kind of protocols such as WRP, CGSR, DSDV and comparison between them, Demand Driven (On-Demand) with six type of protocols such as TORA, DSR, AODV, ABR, CEDAR and SSR and comparison between them shows in Table 4. Finally, shows compare the main characteristics of existing multipath routing protocols in Table 5.

* CEDAR, TORA itself, although it can not also be used in multicasting, but there have been constructed in the two above the multicast routing protocol was proposed.

\subsubsection{Challenges and issues of MANETs}

For ad hoc networking design and implementation, there lots of factors and challenges which are:

Scalability: in some applications, a MANET can grow to thousands of nodes, such as, battlefield deployments, urban vehicle grids and large environmental sensor fabrics. It is extremely hard to have the scalability handled in a MANET due to the random and unlimited mobility (Perkins et al., 2002). 


\begin{tabular}{|c|c|c|c|}
\hline & $\begin{array}{l}\text { Table } \\
\text { Driven(Proactive) }\end{array}$ & Demand Driven(Reactive) & Hybrid \\
\hline \multirow[t]{2}{*}{ Routing Protocols } & DSDV,CGSR,WRP & AODV,DSR,TORA,ABR,SSR & ZRP \\
\hline & & & Lower for \\
\hline $\begin{array}{l}\text { Route acquisition } \\
\text { delay }\end{array}$ & Lower & Higher & $\begin{array}{l}\text { Intra-zone; } \\
\text { Higher for } \\
\text { Inter-zone }\end{array}$ \\
\hline Control overhead & High & Low & Medium \\
\hline Power requirement & High & Low & Medium \\
\hline $\begin{array}{l}\text { Bandwidth } \\
\text { requirement }\end{array}$ & High & Low & Medium \\
\hline
\end{tabular}

Table 2. Illustrates the comparison between Table Driven, Demand Driven and Hybrid

\begin{tabular}{|c|c|c|c|}
\hline Table Driven & CGSR & WRP & DSDV \\
\hline Routing philosophy & Hierarchical & Flat & Flat \\
\hline Loop-free & Yes & $\begin{array}{l}\text { Yes, but } \\
\text { instantaneous }\end{array}$ & not Yes \\
\hline Number of required tables & 2 & 4 & 2 \\
\hline $\begin{array}{l}\text { Frequency of update } \\
\text { transmissions }\end{array}$ & Periodically & $\begin{array}{l}\text { Periodically and } \\
\text { needed }\end{array}$ & $\begin{array}{l}\text { as Periodically and as } \\
\text { needed }\end{array}$ \\
\hline Updates transmitted to & $\begin{array}{l}\text { Neighbors and cluster } \\
\text { head }\end{array}$ & Neighbors & Neighbors \\
\hline Utilize hello messages & No & Yes & Yes \\
\hline Critical nodes & Cluster head & No & No \\
\hline Communication complexity & $\mathrm{O}(\mathrm{x}=\mathrm{N})$ & $\mathrm{O}(\mathrm{x}=\mathrm{N})$ & $\mathrm{O}(\mathrm{x}=\mathrm{N})$ \\
\hline
\end{tabular}

Table 3. Shows the Table-Driven for the three kinds of protocols and comparison between them

Mobility is at most the first designer's enemy of MANET (Murthy and Mano, 2004).

Energy conservation most ad hoc nodes, such as Personal Digital Assistants (PDAs), sensors and Laptops are often power supplied using batteries which have limited power. Therefore, for MANET, energy conservation is considered to be an enormous challenge.

Application/Market penetration: multi-hop technology is not commercial at present. More clearly, the short coverage area's limitation of the wireless products can be justified in its belonging to the standard of IEEE 802.11.

Design/Implementation: manageable, secure, reliable and survivable implementation and design must act for MANET since a bandwidth-constrained operation and a limited physical security are contained in MANETs.

Limited wireless transmission range depends on the wireless technology's capabilities.

Operational/Business-related how to have the network managed and how to bill for services.

The main key issues that affect the design, deployment, and performance of an ad hoc wireless system are summarized as following: scalability, security, energy management, QoS provisioning, deployment considerations, self organization, multicasting, pricing scheme, medium access scheme, routing, transport layer protocols, addressing and service discovery. 


\begin{tabular}{|c|c|c|c|c|c|c|}
\hline On-Demand & TORA & DSR & AODV & ABR & \multicolumn{2}{|c|}{ CEDARSSR } \\
\hline Overall complexity & High & \multicolumn{3}{|c|}{ Medium Medium High } & High & High \\
\hline Overhead & Medium & Medium & Low & High & High & High \\
\hline Routing philosophy & Flat & Flat & Flat & Flat & $\begin{array}{l}\text { Core- } \\
\text { Extracte }\end{array}$ & Elat \\
\hline Loop Free & Yes & Yes & $\mathrm{P}$ & Yes & Yes & Yes \\
\hline Multicast capability & $\mathrm{No}^{*}$ & No & Yes & No & $\mathrm{No}^{*}$ & No \\
\hline Beaconing requirements & No & No & No & Yes & Yes & Yes \\
\hline Multiple route support & Yes & Yes & No & No & No & No \\
\hline Routes maintained in & $\begin{array}{l}\text { Route } \\
\text { table }\end{array}$ & $\begin{array}{l}\text { Route } \\
\text { cache }\end{array}$ & $\begin{array}{l}\text { Route } \\
\text { table }\end{array}$ & $\begin{array}{l}\text { Route } \\
\text { table }\end{array}$ & $\begin{array}{l}\text { Route } \\
\text { table }\end{array}$ & $\begin{array}{l}\text { Route } \\
\text { table }\end{array}$ \\
\hline $\begin{array}{l}\text { Route reconfiguration } \\
\text { methodology }\end{array}$ & $\begin{array}{l}\text { Link } \\
\text { revers }\end{array}$ & $\begin{array}{l}\text { Erase } \\
\text { I route }\end{array}$ & $\begin{array}{l}\text { Erase } \\
\text { route }\end{array}$ & $\begin{array}{l}\text { Localiz } \\
\text { broadc } \\
\text { query }\end{array}$ & $\begin{array}{l}\text { lidynami } \\
\text { asbute } \\
\text { re-comp }\end{array}$ & $\begin{array}{l}{ }^{\text {E Erase }} \\
\text { route } \\
\text { pute }\end{array}$ \\
\hline
\end{tabular}

Table 4. Shows the Demand Driven (On-Demand) with six types of protocols and comparison between them

\begin{tabular}{llllllll}
\hline & AODV DSR & CBRP & DSDV & WRP & GSR & FSR \\
\hline Routing Category & \multicolumn{4}{l}{ ReactiveReactiveReactiveProactiveroactiveroactiveroactive } \\
TTL Limitation & Yes & Yes & Yes & No & No & No & No \\
Flood Control & No & No & No & Yes & Yes & Yes & Yes \\
QoS Support & Yes & Yes & P & Yes & Yes & Yes & Yes \\
Periodic Update & No & No & No & No & No & No & No \\
Power Management & No & No & No & No & No & No & No \\
Multicast Support & Yes & No & No & No & No & No & No \\
Beaconing & Yes & Yes & Yes & Yes & Yes & Yes & Yes \\
Security Support & No & No & No & No & No & No & No \\
\hline
\end{tabular}

Table 5. Shows the comparison of the main characteristics of existing multipath routing protocols

The four important issues significant in MANET are Mobility, QoS Provisioning, Multicasting and Security.

\subsubsection{Mobility}

The mobile user can freely move anywhere and are free to join and move away from the network at anytime. The mobile client can explore the area and can form groups or teams to create a taskforce. In the ad hoc network, the mobile client can have individual random and group mobility and the mobility model can have major impact on the selection of a routing scheme and this directly influences the performance. The mobile clients in MANETs have no physical boundary and their location changes as they move around. This movement of mobile nodes makes the network topology highly dynamic as well as causing the intercommunication patterns between nodes to change frequently in an unpredictable manner (Frodigh et al., 2000), (Satyanarayanan, 2001). Thus, an ongoing communication session suffers frequent path breaks. As a result, broadcasting protocols for MANETs must handle mobility management efficiently (Basagni et al., 1998). 


\subsubsection{QoS provisioning}

A network or a service provider offers the QoS to be the performance level of services the user in terms of many performance metrics of QoS such as packet delivery, the average end-to-end delay, and available bandwidth. Between the network and the host, negotiation is mostly needed when providing QoS (i.e. QoS provision). More specifically, this demand is based on the call admission control, resource reservation schemes and priority scheduling. Therefore, when different levels of QoS are provided in a highly changeable environment, an important issue takes place for this provision. (Chakrabarti and Mishra, 2001).

In MANETs, the provision of QoS is made to be more difficult than providing it in fixed wired networks. This difficulty is due to a high change in network topology, the presence of additional bandwidth, and medium and linked constraints. Static constraints such as memory, processing power and bandwidth, will be only taken into account (Basagni et al., 2004). An implementation must be performed for an adaptive QoS within the traditional resource reservation techniques (Ilyas, 2003), in order that multimedia services in MANETs could be efficiently supported.

\subsubsection{Security}

Security attacks consider Ad hoc networks to be highly vulnerable to it. In the matter fact, this is taken into account to be as the main challenges of the developers of MANET. Particular security problems are involved in a MANET. This is referred to several reasons, such as insecure operating environment, shared broadcast radio channel, malicious attacks of a neighbor node, lack of central authority, limited availability of resources, lack of association among nodes, and physical vulnerability. Integrity, availability, confidentiality, non-repudiation and authentication are the most common attributes of MANETs security system (Ilyas, 2003) (Makki et al., 2007).

Survivability of network services despite the denial of service attacks is ensured by the Availability. Certain information is never disclosed to unauthorized entities. This is ensured by confidentiality. A corruption is never happened for a message being sent. This is ensured by Integrity. In order to ensure the identity of the peer node for communications, a node is enabled by authentication. Finally, the message being sent cannot be denied by the origin of a message. This is guaranteed by non-repudiation (Buttyan and Hubaux, 2007). The major security threats that are available in MANETs are denial of service, passive eavesdropping, signaling attacks, resource of service, host impersonation and information disclosure.

\subsubsection{Multicasting}

Multicast is another significant issue of MANETs because the multicast tree is not static in MANETs due to the random movement of nodes in the network. Multiple hops are potentially contained by routes of each pair of nodes. The single hop communication type is less complex than this type of communication. When multicast packets should be sent to groups in several networks, multicast routing becomes essentially. In MANETs, a vital role is played by multicasting through several applications such as in emergency, military operations and rescue operations. Node mobility with the power and bandwidth constraints make multicast routing very challenging in MANETs (Ritvanen, 2004).

\subsubsection{Application of MANETs}

Mobile ad hoc networks (MANETs) are very flexible networks and suitable for a lot of types of potential applications applied on the Ad hoc networks, as they allow the 


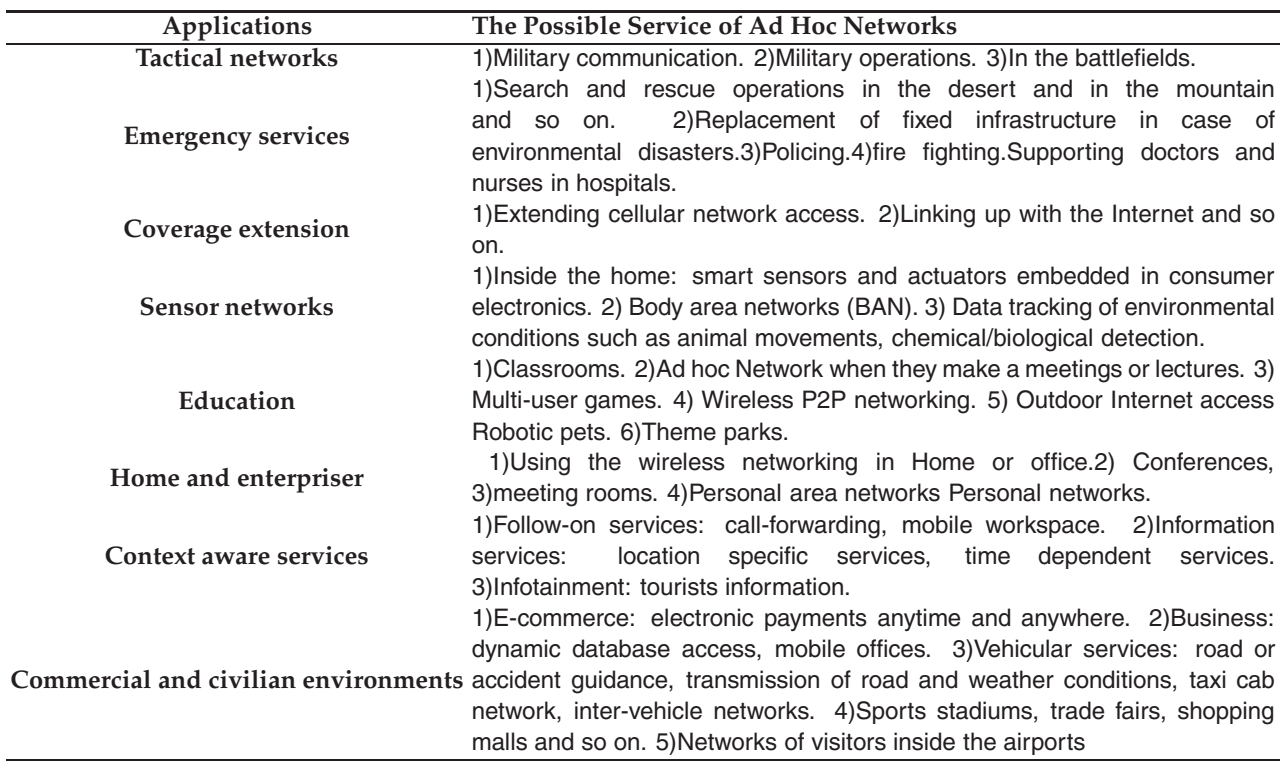

Table 6. Illustrates some of the application for the ad hoc networks

establishment of temporary communication without any pre-installed infrastructure, the application such as the European telecommunications standard institute (ETSI) also the HIPERLAN/2 standard (Masella, 2001) (Habetha et al., 2001), IEEE 802.11 wireless LAN standard family (Crow. B et al., 1997) and Bluetooth (Bluetooth, 2001) the ad hoc network are very important area in this time and very useful for the military (battlefield) and for the disasters (flood, fire and earthquake and so on),meetings or conventions in which people wish to quickly share information (Chlamtac et al., 2003). And then use it in the emergency search-and-rescue operations, recovery, home networking etc. Nowadays, ad hoc network became so important in our circle life, because can be applied anywhere where there is little or without communication infrastructure or may be the existing infrastructure is expensive to use. The ad hoc networking allows to nodes or devices to keep the connections to the network for as long as it's easy to add and to remove to the end of the network. And there are a lot of varieties of applications for the mobile ad hoc networks, ranging large scale such as dynamic network and mobile and small fixed-constrained energy sources. As well as legacy applications that move from the traditional environment to the Ad Hoc infrastructure environments, a great deal of new services can and will be generated for the new environment, finally as the result the mobile Ad Hoc Network is the important technique for the future and to became for the fourth generation $(4 \mathrm{G})$, and the main goals for that to provide propagation the computer environments, that support the users to achieved the tasks to get the information and communicate at anytime, anyplace and from any nodes or devices. And now will present some of these practical applications has been arranged in Table 6 .

These are many applications on ad hoc networks as we mentioned above and in Table 6 provide an overview of present and future MANET applications. However, the following is a summary of the major applications in MANETs such as tactical networks (military battlefield), home and enterprise network (personal area network) etc. 
- Military battlefield, Military equipment currently is equipped with the state of the art computer equipment. Ad hoc networking help the military with the commonplace network technology to maintain information network between military personnel's, vehicles, and military information head quarters. The basic techniques of ad hoc network originated from this field.

- Commercial sector, ad hoc network can be applied in emergency or rescue operations for disaster relief efforts for example in fire, flood, or earthquake and so on. Emergency rescue operations will go to places where communications are impermissible. Therefore proper infrastructure and rapid deployment of a communication network is badly needed. Information is relayed from one rescue team member to another over a small handheld device. Other commercial application includes for instance ship to ship ad hoc mobile communication and so on.

- Local level, ad hoc networks can autonomously link immediate and temporary multimedia network by using notebook or palmtop computers to distribute and allocate information among conference or classroom participants. Besides, it can also be applied for home networks where devices can be link; other examples include taxicab, sports stadium, boat and small aircraft.

- Personal Area Network (PAN), short-range MANET can simplify the intercommunication between a lot of mobile devices such as a PDA, a laptop, and a cellular phone and there are a lot of new devices in this for MANETs. Wired cables can easily be replaced with wireless connections. Ad hoc network enhances the access to the Internet or other networks by means of Wireless LAN (WLAN), GPRS, and UMTS. The PAN is an upcoming application field of MANET for the future computing technology.

- Personal communications (i.e. cell phones, laptops and ear phone).

- Cooperative environments (i.e. meeting rooms, sports stadiums, boats etc.).

- Conferencing (i.e. using mobile nodes).

- Home Network (almost used for PANs).

- Wireless Mesh Networks (very reliable networks that are closely related to MANETs, the nodes of a mesh network generally are not mobile).

- Hybrid Wireless Networks (the goal is to cost savings, enhanced resilience to failures and performance improvements).

- Wireless Sensor Networks (a very active research area of ad hoc networking which includes fixed networks or mobile sensors (Sarkar et al., 2008).

\subsubsection{MANET layers}

The network architecture can be described using a reference the model. More obviously, the layers of software and hardware are described by this model so that data could be sent among two points, besides, to make it capable for interpellating of multiple devices/applications in a network. In order to increase compatibility in the network between different components from different manufacturers, reference models are required for so (White, 2002). Seven layers are contained in the International Organization for Standardization (ISO/IEC, 2003) which proposed the Open Systems Interconnection (OSI) reference model. In the matter of fact, these layers are ordered from the lowest to the highest layer. The lowest layer represents layer one whereas the highest layer represents layer seven as shown in Figure 9. In other words, these layers are respectively ordered as: application layer, presentation layer, session layer, transport layer, network layer, data link layer and physical layer (from the highest to the 


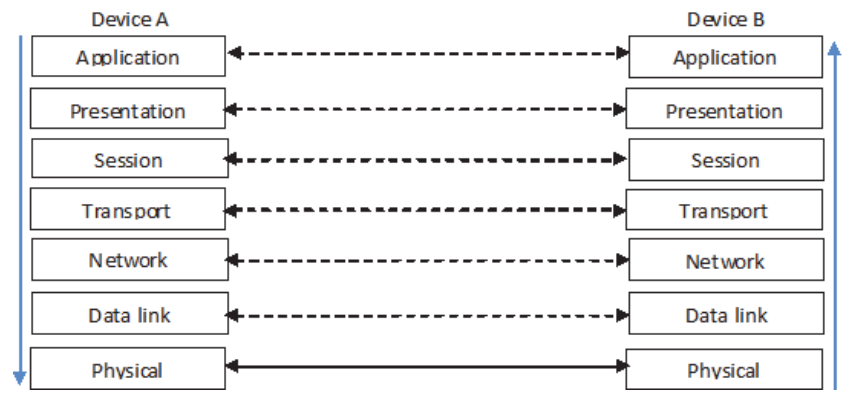

Fig. 9. Illustrates of the original International Organizations for Standardization (ISO) and Open Systems Interconnection (OSI) reference model.

lowest). The transmission of bits is handled by the physical layer through a communications channel. In addition, other physical specifications are taken into account.Such specifications comprise; modulation techniques, connectors and media choice. The access of multiple nodes is coordinated by the functions of data link layer along to a shared medium, control and address information, error detection code, flow control, Medium Access Control (MAC) addressing and so on. Network layer is responsible for creating, maintaining and ending network connection. It transfers a data packet from node to node within the network. In other words, it is responsible for congestion control, IP addressing, and internet working. The transport layer provides an end to end error-free network connection, and makes sure the data arrives at the destination exactly as it left the source. In order to establish sessions between users, the session layer is the layer that controls such a process. At the same time, a series of functions necessary for presenting the data package properly to the sender or receiver are performed by the presentation layer, for example, such as compression and encryption. The application layer is considered to be as the highest layer that provides the user the ability to efficiently access the network. Frequent reconnection and disconnection with peer applications are handled by this layer as a main role of it. Another role of it is to have services and data transmission among users supported, such as, electronic mail and remote file transfer.

\subsubsection{Summary}

In this chapter, described the necessary an overview for the current literature of Mobile Ad Hoc Network (MANET), covering the main concepts of MANET and the existing wireless mobile network approaches, wireless ad hoc networks, wireless mobile approaches, characteristic, applications, challenges, MANET layers and MANET issues. In particular, mobile ad hoc networks have been classified into two types, MANET and mobile ad hoc sensor network. The traffic types in ad hoc networks which include the Infrastructure wireless LAN and ad hoc wireless LAN are presented in Section 1.2.5. In Section 1.2.6 highlight the relevant details about the ad hoc network routing protocol performance issues. The types of ad hoc protocols such as (Table-driven, On-demand and Hybrid) and Compare between Proactive versus Reactive and Clustering versus Hierarchical are in Section 1.2.7. And Section 1.2.8 respectively. The existing ad hoc protocols are presented in Section 1.2.9. The four important issues significant in MANET are Mobility, QoS Provisioning, Multicasting and Security is presented in Section 1.2.10. Furthermore, in Section 1.2.11 and Section 1.2.12 shows the practical application and the layers of the MANET. 


\section{Appendix A}

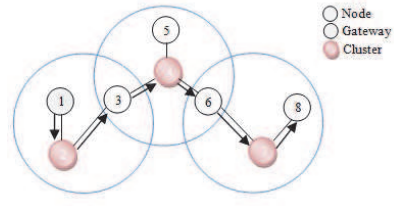

(a) CGSR routing from node 1 to node 8

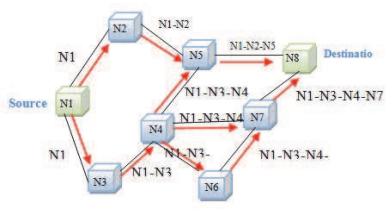

(d) DSR route request
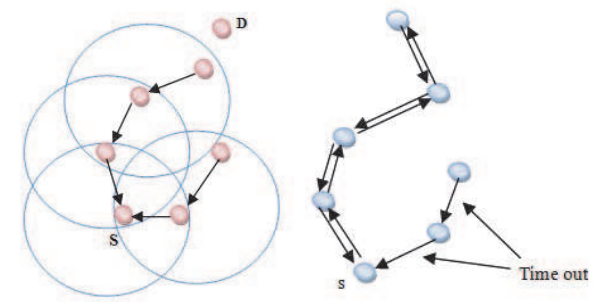

(b) AODV reverse path (c) AODV forward path formation formation

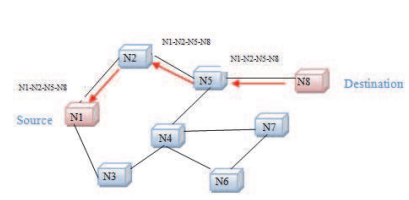

(e) DSR route reply

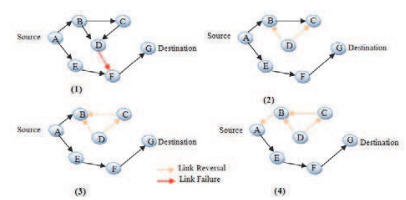

(f) TORA route maintenance

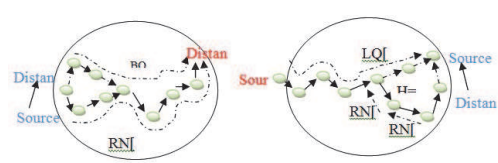

(g) ABR route maintenance Route maintenance for a source move. (B) Router maintenance for a destination move.

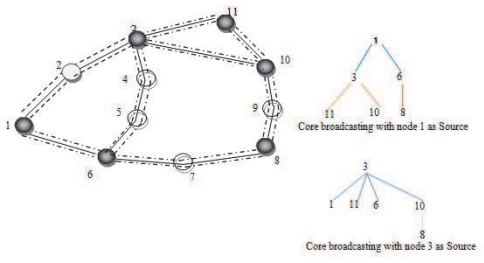

(h) CEDAR core broadcast

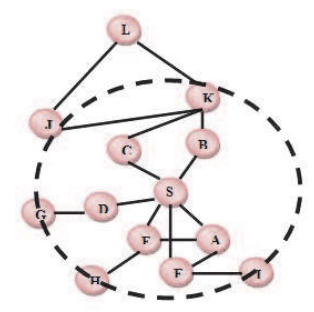

(i) ZRP a routing zone with radius $=2$ (hops)

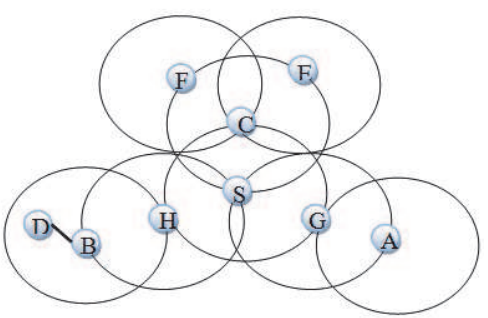

(j) ZRP interzone operation

Fig. 10. illustrates the exiting Mobile ad Hoc network Protocols 


\section{References}

[1] Akkaya, K. and Younis, M. (2005) A survey on routing protocols for wireless sensor networks. In Ad-hoc Networks (2005). Vol.3, N0.2,pp. 325-349.

[2] Akyildiz, I. F., Su, W., Sankarasubrmanina, Y. and Cayirci, E. (2002) A Survey on Sensor Networks. IEEE Communications Magazine (August 2002), pp.102-114.

[3] Asif, H. M. (2009) http://mobius.cs.uiuc.edu/publications/SECON04.pdf. Computer Engineering Department Saudi Arabia King Fahd University of Petroleum and Minerals.

[4] Crow. B, Widjaja, I.and Sakai, P. (1997) Investigation of the IEEE 802.11 medium access control (MAC) sublayer functions. In Proceedings of the INFOCOM '97,Sixteenth Annual Joint Conference of the IEEE Computer and Communications Societies., pp. 66-43.

[5] Bakht, H. (2010) WIRELESS INFRASTRUCTURE, Sensor networks and ad-hoc networking. http://www.computingunplugged.com/issues/issue200410/0000139 8001.html, (accessed on 4 Feb 2011).

[6] Basagni, S., Conti, M., Giordano, S.and Stojmenovic, I "'" (2004) Mobile Ad Hoc Networking, A John Wiley and Sons, Inc., Publication.

[7] Basagni, S., Chlamtac, I., Syrotiuk, V. R. and Woodward, B. (1998) A distance routing effect algorithm for mobility (DREAM) for wireless networks. Proceedings 4th Annual ACM/IEEE International Conference on Mobile Computing Networking (MobiCom), pp. 76-84.

[8] Bluetooth (2001) Specification of the Bluetooth system, Core, v1.1. Bluetooth SIG. (http://www.bluetooth.com)

[9] Broch. J, David .A and David. B. (1998) "A Performence comparison of multi-hop wireless ad hoc network routing protocols". Proc. IEEE/ACM MOBICOM'98, pp.85-97.

[10] Buttyan, L. and Hubaux, J.-P. (2007) "Security and Cooperation in Wireless Networks, Thwarting Malicious and Selfish Behavior in the Age of Ubiquitous Computing", A Graduate Textbo ok, Available on http : / / secowinet.epf l.ch under a permission from Cambridge University Press, Draft Version 1.3, Feb. 2007.

[11] Charabarti, S. and Mishra, A. (2001) QoS Issues in Ad Hoc Wireless Networks. IEEE Communications Magazine, February 2001.

[12] Chen, T. and Gerla, M. (1998) Global state routing: A new routing scheme for ad hoc wireless networks. in Proceedings of IEEE ICC'98, Vol. 1, No. 7-11, pp.171 - 175.

[13] Chlamtac, I., Conti, M. and Liu, J. J (2003) Mobile ad hoc networking: imperatives and challenges. Ad Hoc Networks, Vol. 1, No. 1, pp. 13-64.

[14] Estrin, D., Govindan, R. and Hedemann, J. (1999) New Century Challenges: Scalable Coordination in Sensor Networks. ACM, Mobicom, 1999.

[15] Etsi, E. T.(1999) High Performance Radio Lo cal Area Network Type 2 (Hiperlan2), Broadband Radio Access Networks (BRAN) project, 1999. On the URL:http : //portal.etsi.org/archiv ed/radio/hiperlan/hiperlan.asp.

[16] Freebersyser, J. A. and Leiner, B. (2001) A DoD perspective on mobile ad hoc networks. In: Perkins, C.(Ed.) Ad Hoc Networking, Addison Wesley, Reading, MA, 2001, pp. 29-51.

[17] Frodigh, M., Johansson, P. and Larsson., P. ( 2000) Wireless ad hoc networking: the art of networking without a network Ericsson Review. Vol.5, No.4, pp. 248-263.

[18] Haas, Z. J. and Pearlman, M. R. (2000) The Zone Routing Protocol (ZRP) for Ad Hoc Networks. Internet draft, http://www.ics.uci.edu/ atm/adhoc/papercollection/ haas-draft-ietf-manet-zone-zrp-00.txt.

[19] Habetha, J., Mangold, S. and Wiegert, J. (2001) 802.11 versus HiperLAN/2 - a comparison of decentralized and centralized MAC protocols for multihop ad hoc radio 
networks. in Proceedings of 5th World Multiconference on Systemics, Cybernetics and Informatics, Orlando, USA, pp. 33-40.

[20] Hekmat, R. (2006) Ad-hoc Networks: Fundamental Properties and NetworkTopologies, A book published by Springer.

[21] IEEE (2004) Std 802.16-2004 TM, IEEE Standard for Local and Metropolitan Area Networks - Part 16: Air Interface for Fixed Broadband Wireless Access Systems.

[22] IEEE (2005a) Part 16: Air Interface for Fixed and Mobile Broadband Wireless Access Systems. IEEE 806.16e, IEEE P802.16e/D12.

[23] IEEE (2005b) Std 802.16e-2005TM, IEEE Standard for Local and Metropolitan Area Networks, Part 16: Air Interface for Fixed and Mobile Broadband Wireless Access Systems, Feb 2006.

[24] IEEE (2011) 802 Working group. [Online] http://www.ieee802.org/IEEE 802 LAN/MAN Standards Committee.

[25] IETF-MANET IETF MANET Working Group. http:// www.ietf.org/ html.charters / manetcharter.html.

[26] IETF-MANET IETF Working Group: Mobile Adhoc Networks (manet). http://www. ietf.org/html. charters / manetcharter.html.

[27] IETF (1999) RFC 2501 - Mobile Ad hoc Networking (MANET): Routing Protocol Performance Issues and Evaluation Considerations. http://www.faqs.org / $\mathrm{rfcs}$ /rfc-sidx26.html.

[28] Ilyas, M. (2003) The Handbook of Ad Hoc Wireless Networks (Electrical Engineering Handbook) [Hardcover], CRC Press 2003.

[29] ISO/IEC (2003) Draft ITU-T Recommendation and Final Draft International Standardof Joint Video Specification (ITU-T Rec. H.264 | ISO/IEC 14496-10 AVC). Joint Video Team of ITU-T and ISO/IEC JTC 1, JVT G050r1.

[30] Iwata, A., Chiang, C.-C., PEI, G., Gerla, M. and Chen, T.-W. (2002) Scalable Routing Strategies for Ad Hoc Wireless Networks. IEEE Journal on Selected Areas in Communications, Special Issue on Ad-Hoc Networks, Vol. 17, Issue. 8, pp.1369 - 1379.

[31] Broch. J, Johnson. D and D. Maltz, T. (2004) he Dynamic Source Protocol for Mobile Ad hoc Networks. http:/ / www.ietf.org/internet-drafts/draft-ietf-manet-dsr- 10.txt, IETF Internet draft, 19 July 2004.

[32] Jiang, M., Li, J. and Tay, Y. C. (1999) Cluster Based Routing Protocol. August 1999 IETF Draft. http:/ / www.ietf.org/internet-drafts/draft-ietf-manetcbrp-spec-01.txt.

[33] Johnson, J. B. D. B. and Maltz, D. A. (1999.) The dynamic source routing protocol for mobile ad hoc networks. IETF MANET Working Group, Internet-Draft, October 1999.

[34] Jubin, J. and Tornow, J. D. (1987) The DARPA Packet Radio Network Protocols. proceedings of the IEEE, January, 1987, vol. 75, no. 1, pp.21-32.

[35] Saleh Ali AL-OMARI, and Putra Sumari. (2010) AN OVERVIEW OF MOBILE AD HOC NETWORKS FOR THE EXISTING PROTOCOLS AND APPLICATIONS International journal on applications of graph theory in wireless ad hoc networks and sensor networks, Vol. 2, No.1, pp. 87-110.

[36] LEHR, W. and MCKNIGHT, L. W. (2003) Wireless Internet Access: 3G vs. WiFi? Telecommunication Policy, Vol. 27,No.5, pp. 351-370.

[37] Leiner, B., Ruth, R. and Sastry. A. R (1996)" Goals and challenges of the DARPA GloMo program. IEEE Personal Communications, December 1996., Vol. 3, No. 6, pp. 34-43.

[38] Li, X. (2006) Multipath Routing and QoS Provisioning in Mobile Ad hoc Networks. Department of Electronic Engineering. Queen Mary, University of London, PhD thesis.

[39] Liu, C.-H. and Chang, S.-S. (2009) The study of effectiveness for ad-hoc wireless network. Proceedings of the 2nd International Conference on Interaction Sciences: Information Technology, Culture and Human, Vol. 403, No.6, pp.412-417. 
[40] Makki, S. K., Reiher, P. and Makki, K. (2007) Mobile and Wireless Network Security and Privacy, Springer Science and Business Media, LLC, 2007.

[41] Masella, A. K. A. A. (2001) Serving IP quality of service with Hiper- LAN/2. Computer Networks: The International Journal of Computer and Telecommunications Networking - Wireless networking, Vol. 37, issue. 1, pp. 17-24.

[42] Mbarushimana, C. and Shahrabi, A. (2008) Type of service aware routing protocol in mixed traffic Mobile Ad Hoc Networks. IEEE International Symposium On Wireless Communication Systems ( ISWCS '08),Reykjavik pp.677-681.

[43] Mohapatra, P. and Krishnamurthy, S. V. (2005) Ad Hoc Networks Technologies and Protocols", Springer, 2005.

[44] Morinaga, N., Kohno, R. and Sampei, S. (2002) Wireless Communication Technologies New Multimedia Systems", Kluwer Academic Publishers, 2002.

[45] Murthy, C. S. R. and Mano, B. (2004) Ad Hoc Wireless Networks: Architectures and Protocols, Prentice Hall PTR.

[46] Murthy, S. and Garcia-luna-aceves, J. J. (1996) An efficient routing protocol for wireless networks. ACM Mobile Networks and Applications Journal, pp.183-197.

[47] Maltz, J.B. and D. Johunson, (2005). "Lessons from a full-Scale multi-hop wireless ad hoc network test bed". IEEE Personal communications magazine.

[48] Nicopolitidis, P., Obaidat, M. S., Papadimitriou, G. I. and Pomportsis, A. S. (2003) Wireless Networks. John Wiley and Sons, Ltd.

[49] Pandey, A. K., and Fujinoki, H(2005)." Study of MANET routing protocols by GlomoSim simulator. International Journal of Network Management", November 2005, Vol 15, pp.393 -410.

[50] Part-11 (1997) IEEE Computer Society LAN MAN Standards Committee, Wireless LAN medium access control(MAC) and physical layer (PHY) specifications, IEEE standard 802.11, 1997. The Institute of Electrical and Electronics Engineers, New York, NY.

[51] Part-12 (1999) IEEE Computer Society. IEEE standard for information technology telecommunications and information exchange between systems - local and metropolitan networks - specific requirements.

[52] Part-16 (2004) IEEE Standard for Local and metropolitan area networks Part 16: Air Interface for Fixed Broadband Wireless Access Systems, IEEE Std 802.16-2004, 2004.

[53] Perkings, C. E., M, E., belding-royer and Das. R. S. (2003) Ad Hoc OnDemand Distance Vector (AODV) Routing. http://www.ietf.org/internetdrafts/ draft-ietf-manet-aodv-13.txt, IETF Internet draft,RFC.

[54] Perkins, C. E. (2001) Ad hoc networking: an introduction, Addison-Wesley Longman Publishing Co., Inc. Boston, MA, USA 1'2001,pp. 1 - 28, ISBN: 0-201-30976-9.

[55] Perkins, C. E. and Bhagwat, P. (1994) Highly Dynamic Destination-Sequenced Distance-Vector Routing (DSDV) for Mobile Computers. $n$ Proceedings of ACM SIGCOMM, pp.234-244.

[56] Perkins, D. D., Hughes, H. D. and Owen, C. B. (2002) Factors A ecting the Performance of Ad Hoc Networks. IEEE internet computing, East Lansing, 2002, MI 48824-1226.

[57] Park,V. and S. Corson. (2001)." Temporally-ordered Routing algorithm (TROA)". Internet Draft, draftietf-manet-tora-spec-04-txt. July,2001.

[58] Ritvanen, K. (2004) Multicast Routing and Addressing. Helsinki University of Technology Department of Computer Science and Engineering, A Seminar on Internetworking.

[59] Sarkar, S. K., Basavaraju, T. G. and Puttamadappa, C. (2008) Ad Hoc Mobile Wireless Networks: Principles, Protocols, and Applications, Auerbach Publications Taylor and Francis Group. 
[60] Sinha .P , R.Sivakumar, V. Bharghavan,"CEDAR: a Core-Extraction Distributed Ad hoc Routing algorithm". IEEE INFOCOM'99, Vol 4, No.2, pp. 120-127.

[61] Satyanarayanan, M. (2001) IEEE Pervasive Computing:Vision and Challenges. Personal Communication, Vol. 8, No. 2, pp. 10 -17.

[62] White, C. (2002) Data Communications and Computer Networks, Published by Thomson, Third Edition, 2002.

[63] Wu, S.-L., Yu-chee and TSENG (2007) Wireless Ad Hoc Networking. Auerbach Publications -Taylor and Francis Group. 


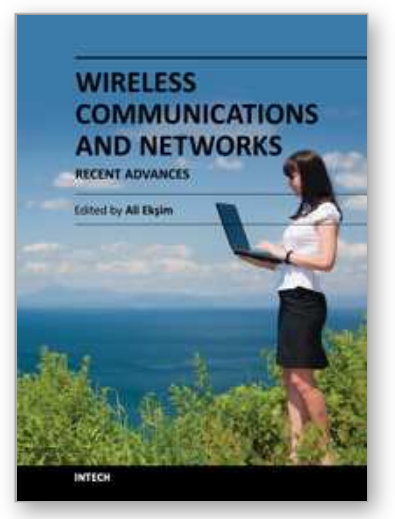

\author{
Wireless Communications and Networks - Recent Advances \\ Edited by Dr. Ali Eksim
}

ISBN 978-953-51-0189-5

Hard cover, 596 pages

Publisher InTech

Published online 14, March, 2012

Published in print edition March, 2012

This book will provide a comprehensive technical guide covering fundamentals, recent advances and open issues in wireless communications and networks to the readers. The objective of the book is to serve as a valuable reference for students, educators, scientists, faculty members, researchers, engineers and research strategists in these rapidly evolving fields and to encourage them to actively explore these broad, exciting and rapidly evolving research areas.

\title{
How to reference
}

In order to correctly reference this scholarly work, feel free to copy and paste the following:

Saleh Ali Alomari and Putra Sumari (2012). Multimedia Applications for MANETs over Homogeneous and Heterogeneous Mobile Devices, Wireless Communications and Networks - Recent Advances, Dr. Ali Eksim (Ed.), ISBN: 978-953-51-0189-5, InTech, Available from: http://www.intechopen.com/books/wirelesscommunications-and-networks-recent-advances/multimedia-applications-for-mobile-ad-hoc-networks-overhomogeneous-and-heterogeneous-mobile-devices

\section{INTECH}

open science | open minds

\section{InTech Europe}

University Campus STeP Ri

Slavka Krautzeka 83/A

51000 Rijeka, Croatia

Phone: +385 (51) 770447

Fax: +385 (51) 686166

www.intechopen.com

\section{InTech China}

Unit 405, Office Block, Hotel Equatorial Shanghai

No.65, Yan An Road (West), Shanghai, 200040, China

中国上海市延安西路65号上海国际贵都大饭店办公楼 405 单元

Phone: +86-21-62489820

Fax: +86-21-62489821 
(C) 2012 The Author(s). Licensee IntechOpen. This is an open access article distributed under the terms of the Creative Commons Attribution 3.0 License, which permits unrestricted use, distribution, and reproduction in any medium, provided the original work is properly cited. 